\title{
Evaluation of Additives as Corrosion Inhibitors/Antioxidants for High Quality Nano Emulsifiable Oils of Metalworking Fluids
}

\author{
Noura El Mehbad \\ Faculty of Science, Najran University, Najran, KSA \\ Email: abdelazimomar@hotmail.com
}

Received 10 February 2014; revised 8 March 2014; accepted 5 April 2014

Copyright (C) 2014 by author and Scientific Research Publishing Inc. This work is licensed under the Creative Commons Attribution International License (CC BY). http://creativecommons.org/licenses/by/4.0/

(c) (i) Open Access

\section{Abstract}

Surfactants used for formulation metal working fluids. In the present paper, the inhibitive effect of synthesized anionic surfactant $P$-decyloxy p-sodium sulphonateazobenzene with chemical structure $\mathrm{H}_{21} \mathrm{C}_{10} \mathrm{O}-\mathrm{Ph}-\mathrm{N}=\mathrm{N}$-Ph- $\mathrm{SO}_{3} \mathrm{Na}$ and 1-ethyl-1-dodecyl-2-sulphonate-4-(hydroxyl ethyl)-piprazine on the corrosion of carbon steel in sulphuric acid solution is measured by the weight loss method. The relationships between the concentrations of these inhibitors and their surface properties, thermodynamic properties, surface coverage and inhibiting efficiency, have been investigated. The results indicate that P-decyloxy p-sodium sulphonate azobenzene is superior to 1-ethyl-1-dodecyl-2-sulphonate-4-(hydroxyl ethyl)-piprazine at high acid concentration. These inhibitors blend with coupling agent to produce water miscible cutting fluid. Values of surface tension of these additives were measured in water phase and consequently CMC was determined for all inhibitors. The efficiency of these inhibitors depends on their chemical structure and the presence of hydrophilic group to association of the surfactant with metal surface, hence very good wetting properties. The anti-corrosion characteristic of surfactants increases with increasing polar linkages in the aromatic moieties forming chelated and coordinated layer. This is due to the increase in number of sites to chemisorption on the metal surface. These studies have led to much clear evidence of the intimate relationship between the chemical structure of the surfactants and their efficiency. More confirmation for suggested mechanism was investigated by measuring the area occupied per molecule of the surfactant at aqueous phase. The results indicate that the amphoteric surfactant more efficient than anionic surfactant. The antioxidants activities of different dosages of inhibitors were evaluated and suggested mechanism according to their thermodynamics parameters. The oxidation of the oil has been carried for different time intervals. The degradation of the oil has been monitored by total acid formation. 


\section{Keywords}

\section{Lube Oil, Antioxidants, Antiwears, Sulphonates, Ethoxylates, Phase Transfere Catalysts}

\section{Introduction}

Metalworking can be defined as processes of modification of the shape of a metal piece. In all the metalworking processes, a considerable amount of heat is evolved due to the internal friction and the friction between tool and metal. Straight oils are used as rolling fluids for rolling of thin sheets of ferrous and nonferrous metals. Straight oils contain base oils and additives. Paraffinic oils are preferred. Also these additives include corrosion inhibitors. Recently, the mixture of anionic/nonionic polymeric surfactants used as additives for metaworking fluid was studied by Omar 2004 [1].

Most commercial acid inhibitors are organic ammonium salts, organic amine derivatives, organic phosphates, succinimides and imidazoline derivatives [2]-[4]. The inhibitive effects of benzyl triethanol ammonium chloride and its ethoxylated derivative on the corrosion of carbon steel in sulphuric acid were previously investigated [2]. Four cationic corrosion inhibitors having the general formula $\mathrm{ClRN}^{+} \mathrm{H}_{2}\left(\mathrm{CH}_{2}\right)_{\mathrm{n}} \mathrm{N}^{+} \mathrm{H}_{2} \mathrm{RCl}$ where $\mathrm{R}$ is a hydrogen atom or benzyl group, $n=8$ or 10 were applied in sulphuric acid solution at temperature up to $78^{\circ} \mathrm{C}$. It was found that the alkylation processes improved with surface and thermodynamic properties of the surfactant molecules, and consequently more inhibition effects were obtained [3]. The inhibiting effect of cationic surfactant $\mathrm{N}, \mathrm{N}, \mathrm{N}$-dimethyl 4-methylbenzyl dodecyl ammonium chloride on mild steel in hydrochloric acid solution was investigated by surface and thermodynamic measurements, weight loss tests, polarization measurements and EDS techniques. It found that, the corrosion inhibition efficiency of the surfactant compound increases with increasing concentration and reached a maximum value at near the critical micelle concentration (CMC). The inhibitor acts through adsorption phenomenon and formation of barrier film [4]. Some amphoteric surfactants N-Decyl-N-benzyl-N-methylglycine(AB) and N-Dodecyl-N-benzyl-N-methylglycine(CD) were evaluated by author. The physicochemical chemical characteristics were investigated. Surface properties, in particular the critical micelle concentration $(\mathrm{CMC})$, the maximum surface excess $\left(\Gamma_{\mathrm{CMC}}\right)$ and the minimum surface area $\left(\mathrm{A}_{\mathrm{MIN}}\right)$ were measured. It is found the surface and thermodynamic properties of the prepared surfactants depend on their hydrocarbon chain length. Also it is found that there is a good relation between surface properties of the additive and their efficiency in depressing the pour point. The mechanism of the depressants action has been suggested according the adsorption of each additive [5].

In our previous work, the synthesis of new additives as pour point and antioxidants was described [6] [7]. The author study new antioxidant for lube oil. This antioxidant dibenzyl s-phenyl thioglyconitrile and other derivatives were prepared by phase transfere catalysts. These compounds were added to oil in different concentrations. The antioxidants activities of different dosages were evaluated and suggested mechanism according to micelle and its thermodynamic. Novel method of inhibiting oxidation was proposed by author. The mechanism was suggested according to surface activity of additive in oil phase. More confirmation for suggested mechanism was investigated by measuring the area occupied per molecule of additive at oil phase. There is a good relationship between the structure of hydrophilic group of the additive and its efficiency. The antioxidants activities of different dosages were evaluated and suggested mechanism according to micelle and its thermodynamics. The oxidation of the oil has been carried for different acid formation. Oxidation stability of lube oil was largely affected by sulphur and aromatic hydrocarbons concentration in oil, with increased sulphur content increase oxidation stability time intervals. Polyalkylphenol formaldehyde sulphonate and its ethoxylate were synthesized and evaluate as pour point depressant, viscosity improver and antioxidant. The efficiency of these additives depends on their chemical structure and degree. The modification of the lyophobic and lyophilic groups, in the structure of the surfactant, may become necessary to maintain surface activity at a suitable level.

Therefore, it is very important to choose the correct surfactants and optimize its concentration to get full efficiency benefit of using base stock.

The purpose of the present work study of prepared P-decyloxy p-sodium sulphonate azobenzene with chemical structure $\mathrm{H}_{21} \mathrm{C}_{10} \mathrm{O}-\mathrm{Ph}-\mathrm{N}=\mathrm{N}-\mathrm{Ph}-\mathrm{SO}_{3} \mathrm{Na}$ and 1-ethyl-1-dodecyl-2-sulphonate-4-(hydroxyl ethyl)-piprazine as additives in metalworking straight oil formulations for anti-corrosion and anti-oxidant. These additives differ in 
head group of surfactant. The author will suggest the field of action mechanism of the additive according to its surface properties.

\section{Experimental}

\subsection{Formulation of Metal Working Straight Oil}

Base paraffinic oil represents $82 \%$ with the additive (5\%), other coupling agent about 3\% of dodecyl alcohol and sodium oleate about $7 \%$ [8].

\subsection{Synthesis of the Additives}

The following surfactants were prepared and kindly supplied by Omar [9]. Sodium salt of sulphonic acid (0.24) in $100 \mathrm{ml}$ of ethanol was added to $10 \mathrm{ml}$ of concentrated hydrochloric acid. The reaction contents were refluxed for $5 \mathrm{~h}$. Solvents were removed using a rotary evaporator and the residue was dissolved in $100 \mathrm{ml}$ of 1:1 aqueous acetone and $10 \mathrm{ml}$ of concentrated hydrochloric acid, followed by $50 \mathrm{ml}$ of sodium nitrate $(0.3 \mathrm{~mol})$ in an icebath. The diazonium salt solution obtained was added to $100 \mathrm{ml}$ of an aqueous solution of $0.37 \mathrm{~mol}$ of phenol, $0.35 \mathrm{~mol}$ of $\mathrm{NaOH}$ and $0.57 \mathrm{~mol}$ of sosium carbonate and the mixture was stirred for $12 \mathrm{~h}$ at room temperature. Then it was neutrralized with acetic acid and the product was recrystallized to give an orange powder of p-hydroxy —p sodium sulphonate azobenzene with purity of 96\% [9]. Equimolar amounts of p-hydroxy-p sodium sulphonate azobenzen decyl bromide was added to sodium ethoxide solution simultaneously. After refluxing for $4 \mathrm{~h}$, the reaction mixture was poured into $500 \mathrm{ml}$ of ice-water and the resulting product was extracted with chloroform. After removal of chloroform using a rotary evaporator, the product was recrystallized from ethanol to give an orange powder of $\mathrm{H}_{21} \mathrm{C}_{10} \mathrm{O}-\mathrm{Ph}-\mathrm{N}=\mathrm{N}-\mathrm{Ph}-\mathrm{SO}_{3} \mathrm{Na}$.

The second surfactant 1-ethyl-1-dodecyl-2-sulphonate-4-(hydroxyl ethyl)-piprazine was kindly supplied by omar and prepared according to Reference [10].

\subsection{Surface and Interfacial Tension Measurement}

Surface tension of different concentrations for $10^{-7}$ to $0.1 \mathrm{~mol} / \mathrm{L}$ of the synthesized additives was measured by using Kruss Model 8451 in $\mathrm{H}_{2} \mathrm{O}$ at $30^{\circ} \mathrm{C}-50^{\circ} \mathrm{C}$ according to omar et al. [11].

The physicochemical properties of the base oil are listed in the following Table 1 [8].

A carbon steel electrode was used to evaluate the corrosion rate in sulphoric acid medium by the weight loss method. The chemical composition of the steel is (wt\%): C, $0.06-0.2$; Mn, $0.27-0.60 ; \mathrm{P}, 0.048, \mathrm{~S}, 0.056$, and the surface is $3 \mathrm{~cm} \times 3 \mathrm{~cm}$. Before use the electrode is polished successively with emery paper down to 600 grades, degreased with ethyl alcohol, rinesed with doubly distilled water and then weighed.

At optimum conditions the standard test method (ASTM D 4627) was used to evaluate anticorrosion properties of cutting oils. The electrode was placed in baker containing filter paper and diluted metal working fluid in the prescience of the above concentration of sulphoric acid. The best conditions were selected to investigate their surface of samples to determine the corrosion mechanism using scanning electron microscope.

\subsection{Oxidation Stability Study}

The oxidation test was carried out at $120^{\circ} \mathrm{C}$ according to ASTM D 943 standard methods. The base stock sample was subjected to oxidation with pure oxygen at a flow rate of $0.1 \mathrm{~L} /$ hour for maximum 70 hours.

\section{Results and Discussions}

\subsection{Surface and Thermodynamic Properties}

Surface tension of two inhibitors has been measured at different temperatures and for different concentrations. Their values are shown in Table 2. The critical micelle concentration CMC was determined at each temperature, the surface excess concentration $\Gamma_{\max } \times 10^{-11} \mathrm{~mol} / \mathrm{cm}^{-2}$, area occupied per molecule $A_{\min } \mathrm{nm}^{2}$, free energy of micellization molecule $\mathrm{G}^{0} \mathrm{mic} \mathrm{KJ} / \mathrm{mol}$ and free energy of adsorption at solution/air interface $\mathrm{G}^{0} \mathrm{ad} \mathrm{KJ} / \mathrm{mol}$ have been calculated. The results indicate that the CMC of the inhibitors decrease with increasing temperature, while the values of CMC of inhibitors BAM is smaller than ANS. The minimum area per molecule at the aqueous 
Table 1. Physicochemical properties of the base oil.

\begin{tabular}{ccc}
\hline Properties & Base oil & Test \\
\hline Denisty (g/ml) at $15.5 \mathrm{C}$ & 0.8958 & D. 1298 \\
Refactive index nD ${ }^{20}$ & 1.4955 & D. 1218 \\
ASTM colour & 4.5 & D. 1500 \\
Kinematic viscosltycSt & & D. 445 \\
at 40 C & 17.56 & D. 455 \\
at 100 C & 29.15 & ASTM D. 97 \\
Pour point C & 15 & GPC \\
Molecular weight & 520 & Urea adduction \\
Total paraffinic content, wr\% & 59.353 & ASTM D524 \\
Carbon residue contenty, wt $\%$ & 1.9 & ASTM D482 \\
Ash content, wt $\%$ & 0.0511 &
\end{tabular}

Table 2. Surface properties and free energies of surfactants at different temperatures.

\begin{tabular}{|c|c|c|c|c|c|c|c|c|}
\hline Surfactants & $\begin{array}{c}\text { Temperatures } \\
{ }^{\circ} \mathrm{C}\end{array}$ & $\begin{array}{c}\mathrm{CMC} \\
\mathrm{mol} / \mathrm{l} \\
10^{3}\end{array}$ & $\begin{array}{c}\Pi_{\mathrm{CMC}} \\
\mathrm{Mn} / \mathrm{m}^{2}\end{array}$ & $\begin{array}{c}\mathrm{PC}_{20} \\
\mathrm{MOL} / \mathrm{l}\end{array}$ & $\begin{array}{c}\Gamma_{\max } \times 10^{-11} \\
\mathrm{~mol} / \mathrm{cm}^{-2}\end{array}$ & $\begin{array}{l}A_{\min } \\
\mathrm{Nm}^{2}\end{array}$ & $\begin{array}{l}\mathrm{G}^{0} \mathrm{mic} \\
\mathrm{KJ} / \mathrm{mol}\end{array}$ & $\begin{array}{c}\mathrm{G}^{0} \mathrm{ad} \\
\mathrm{KJ} / \mathrm{mol}\end{array}$ \\
\hline \multirow{3}{*}{ ANS } & 25 & 4 & 23 & 1.8 & 3.7 & 0.42 & -27.2 & -36.1 \\
\hline & 35 & 3 & 18 & 1.5 & 3.5 & 0.48 & -27.9 & -36.4 \\
\hline & 45 & 2 & 14 & 1 & 3.1 & 0.51 & -29.6 & -37.2 \\
\hline \multirow{3}{*}{ BAM } & 25 & 0.2 & 25 & 4 & 4.7 & 0.8 & -30.56 & -38.4 \\
\hline & 35 & 0.1 & 12 & 3 & 4.5 & 0.9 & -31.2 & -39.9 \\
\hline & 45 & 0.05 & 8 & 2.1 & 4.1 & 0.93 & -32.7 & -41.2 \\
\hline
\end{tabular}

solution/air interface of BAM is slightly bigger than ANS and slightly increases with increasing temperature, this mean that BAM will increase degree of surface coverage of metal surface. The surface excess concentration decreases with increasing temperature for two inhibitors, while BAM prefers adsorption rather than the other. Studying the results in Table 2 shows that the inhibitors BAM has larger values of effectiveness $\mathrm{PC}_{20}$, efficiency $\Pi_{\mathrm{CMC}}$, maximum surface excess $\Gamma_{\max }$ and minimum surface area $A_{\min }$, indicating that this inhibitor is most efficient one that favors adsorption at the air/ solution interface and gives a greater lowering in surface tension at the CMC. Standard free energies of micellization $G^{0}$ mic and adsorption $G^{0}$ ad are all negative, so micellization of the prepared inhibitors is a spontaneous process and the value increase with increasing temperatures. The standard free energy of adsorption is all negative values for inhibitors, indicating that the inhibitor BAM and ANS have the ability for adsorption at interface. On the other hand, the molecules of inhibitors favour adsorption at interface rather than sharing in the micellization processes.

\subsection{Weight Loss Tests}

The corrosion rate increases with time and tend to slightly increase after 12 days. This due to formation of stable oxide according Omar et al. [2] as shown in Figure 1. Studying the inhibition efficiencies of inhibitors at various concentrations, $0.1 \mathrm{~mol}$ of sulphoric acid and $25^{\circ} \mathrm{C}$ are shown in Figures $2-4$. The efficiency was $97 \%$, 90\%, 85\%, 80\%, 69\%, 78\% and 55\% for 6, 8, 10, 12, 14, 16 and 18 days respectively at 100 ppm of the inhibitor PAM. While for ANS the efficiency was 78\%, 76\%, 73\%, 65\%, 64\%, 60\% and 50\% for 6, 8, 10, 12, 14, 16 and 18 days respectively. This means that BAM is more efficient than ANS at the same concentration and constant temperature. With further increase in inhibitor concentration, the efficiency slightly increases until $1000 \mathrm{ppm}$ the efficiency steady stable. The author suggest the inhibitor tend to adsorb on the metal surface, then the inhibitor molecule tend to degradable with long times (12 days). This behavior is due to the dependence of inhibition efficiency on its surface properties. From Table 2, the area per molecule for PAM is larger than that of ANS. The effect of increasing the temperature from $25^{\circ} \mathrm{C}$ to $45^{\circ} \mathrm{C}$ for $0.1 \mathrm{~mol}$ of sulphuric acid at constant conditions is shown in Figure 5. For 1000 ppm of each inhibitor, the inhibition efficiency decreases with the increase in temperature from $25^{\circ} \mathrm{C}$ to $45^{\circ} \mathrm{C}$. This can be attributed to the decrease in the protective nature of the inhibitive film formed on carbon steel surface at higher temperatures. At the same time the degree of inhibition decreases with 


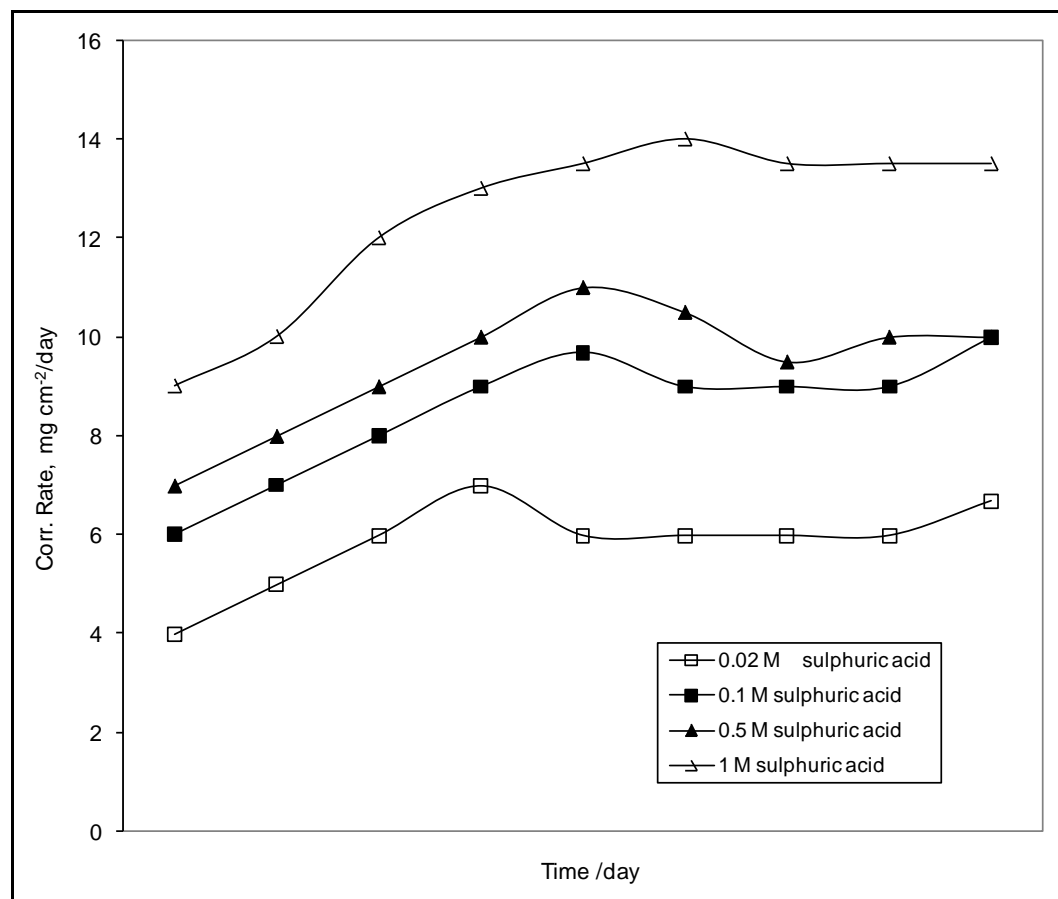

Figure 1. Effect of timee on corrosion rate of carbon steel in various concentration of sulphuric acid.

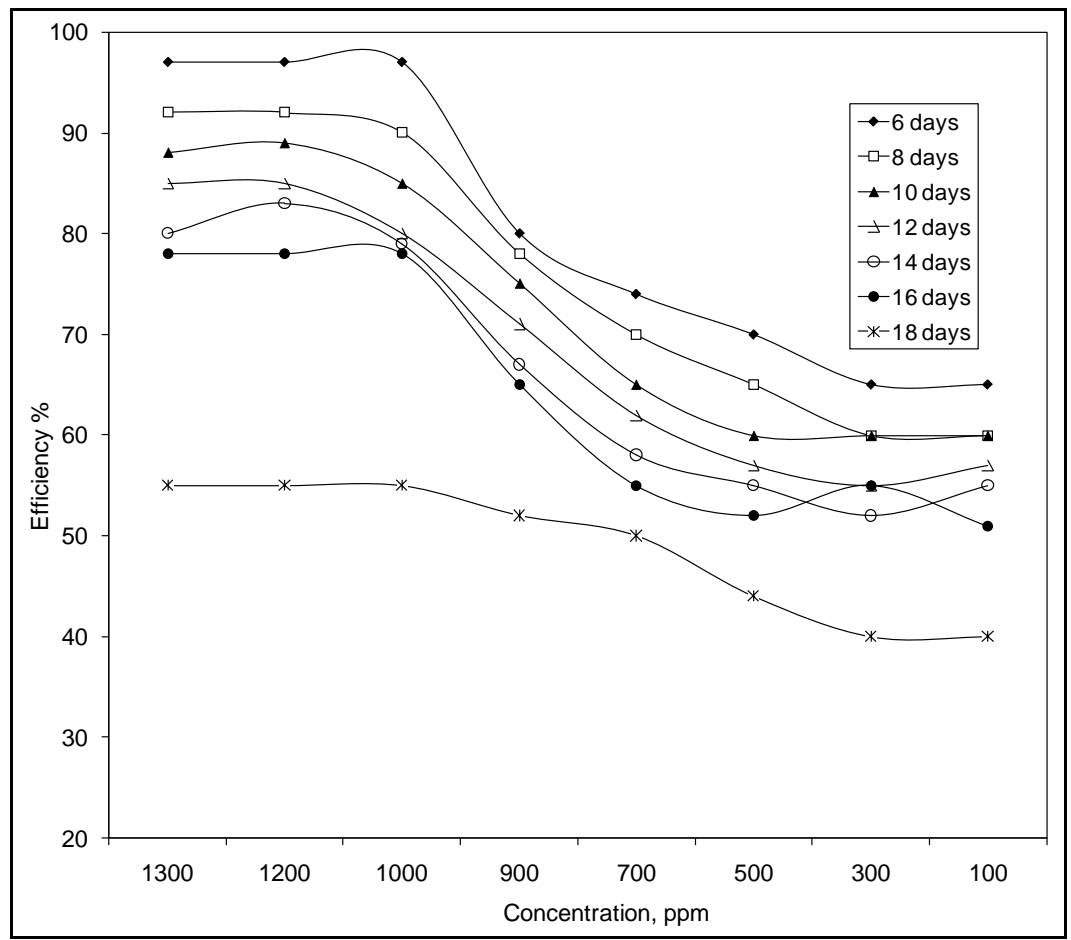

Figure 2. Effect of various concentration from BAM additive on its efficiency in $0.1 \mathrm{Mol}$ sulphoric acid at $25 \mathrm{C}$.

increasing times and temperatures (Figure 5). The author thinks the hydrophilic group of each inhibitor destruct with long time and high temperature. As the results increasing temperature decrease the adsorption and consequently enhance the desorption processes. 


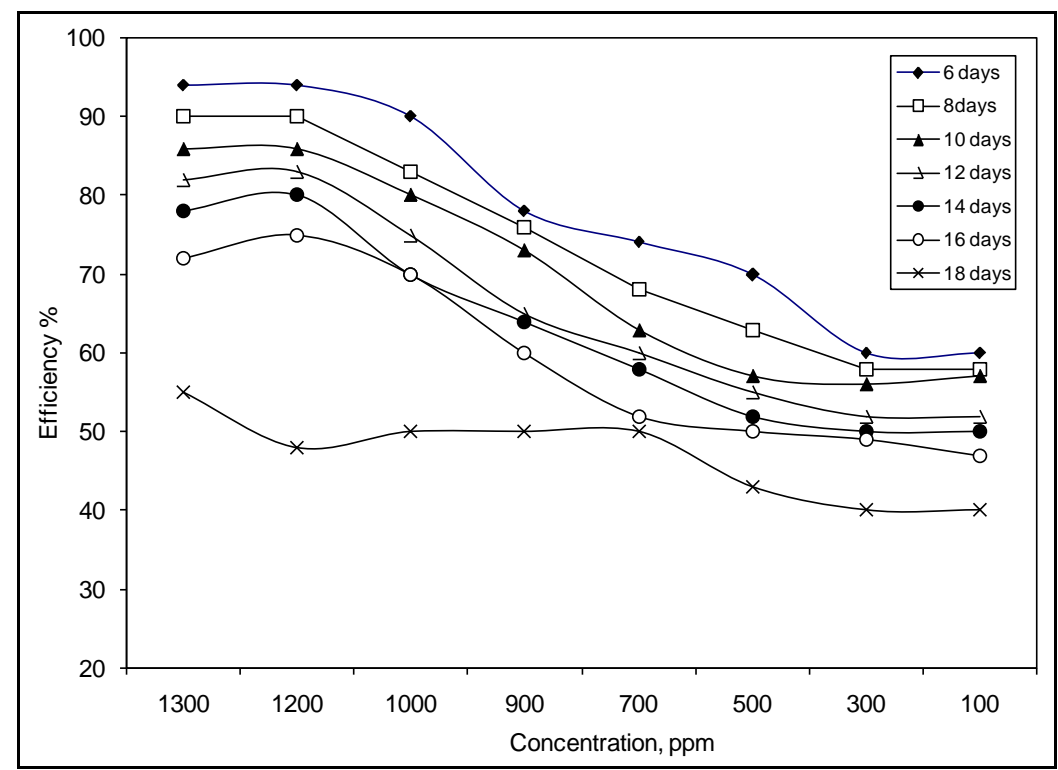

Figure 3. Effect of various concentration from ANS on its efficiency in $0.1 \mathrm{Mol}$ sulphuric acid and $25 \mathrm{C}$.

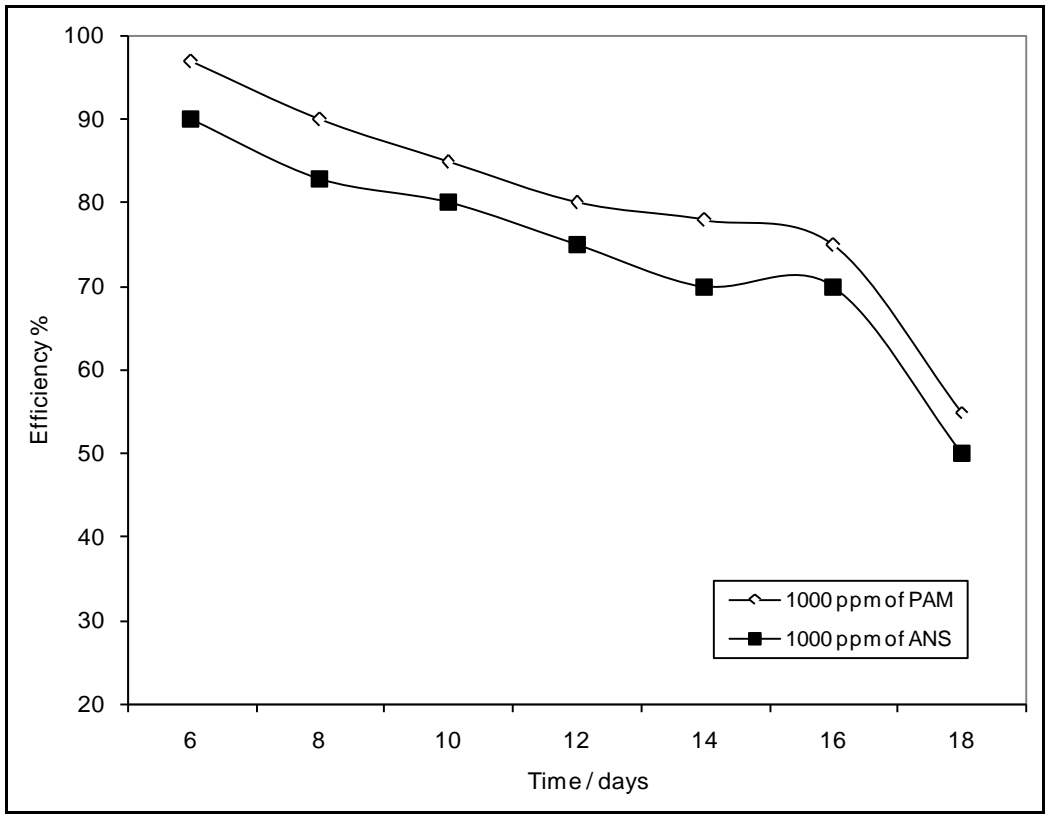

Figure 4. Effect of time on inhibitors efficiency at constant concentration 1000 ppm and $0.1 \mathrm{M}$ of sulphuric acid.

Effect of adding inhibitors on metal working fluid at optimum conditions are shown in Figure 6. It is clear that the efficiency of each inhibitor decreases slightly with increasing time, but the degree of decreasing is slightly smaller in compare in pure acid solution as studying early. This result confirm that the synergism between inhibitors and base oil which form stable emulsion and increase degree of surface coverage on carbon steel surface.

The effect of these inhibitors on the oxidation stability of oil is given in Figure 7. The data show the additive retards the oxidation of oil for limit time and loss its efficiency after 30 hours. The additive BAM is the best; due to it has the best surface properties. The author concludes that the ability and stability of micelle is predominant factor for increase oxidation stability of oil early [5]-[8]. From Figure 7, the total acid decrease by 


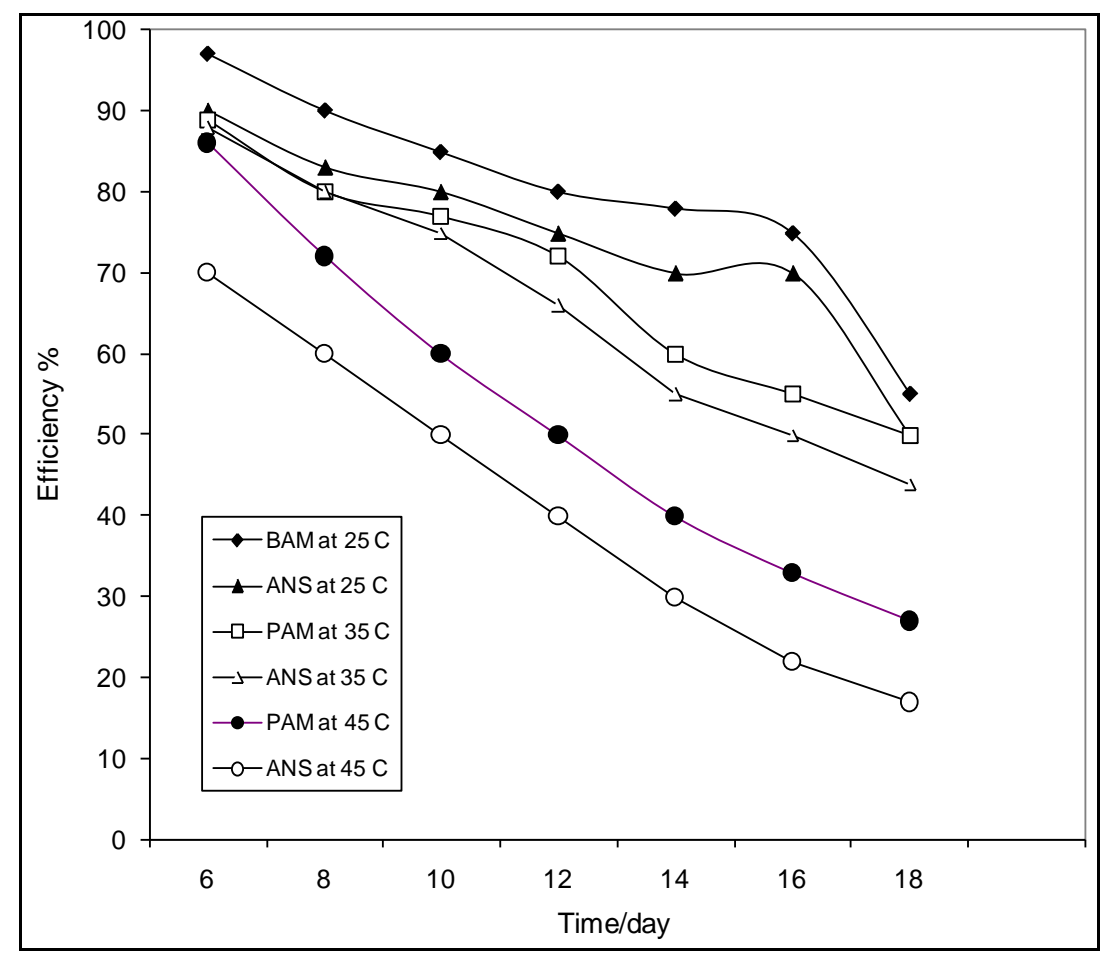

Figure 5. Effect of varying temperature on inhibitors efficiency in $0.1 \mathrm{~m}$ sulphuric acid at $1000 \mathrm{ppm}$.

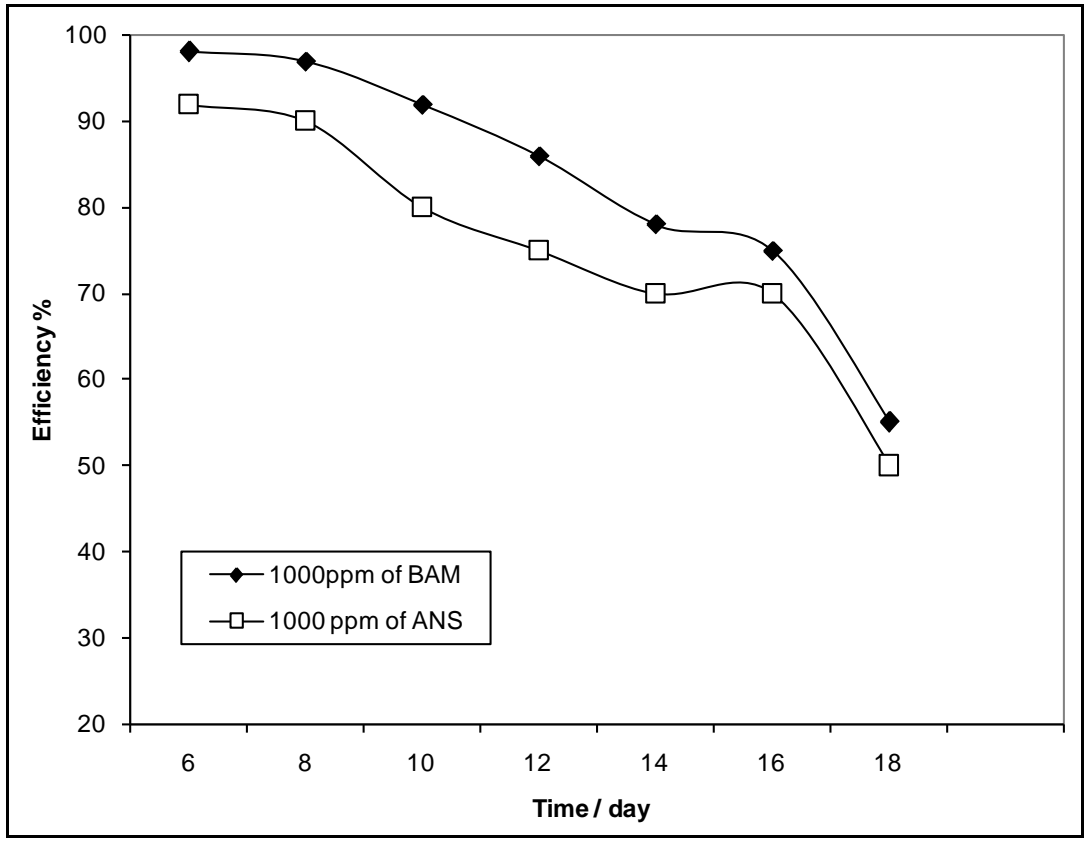

Figure 6. Effect of times by days on corrosion efficiency of inhibitors at concentration $1000 \mathrm{ppm}$ and $25 \mathrm{C}$ in metal working fluid.

increasing the additive concentrations and reach the optimum value near to CMC as confirmed by the author early [5]-[8]. Further increase concentration of the additive, the oxidation stability decrease due to retardation of micelle formation, which affect on interfacial tension and degree of adsorption at interface. The azo group inhibits propagation of free radicals and terminates reaction processes of free radicals. 


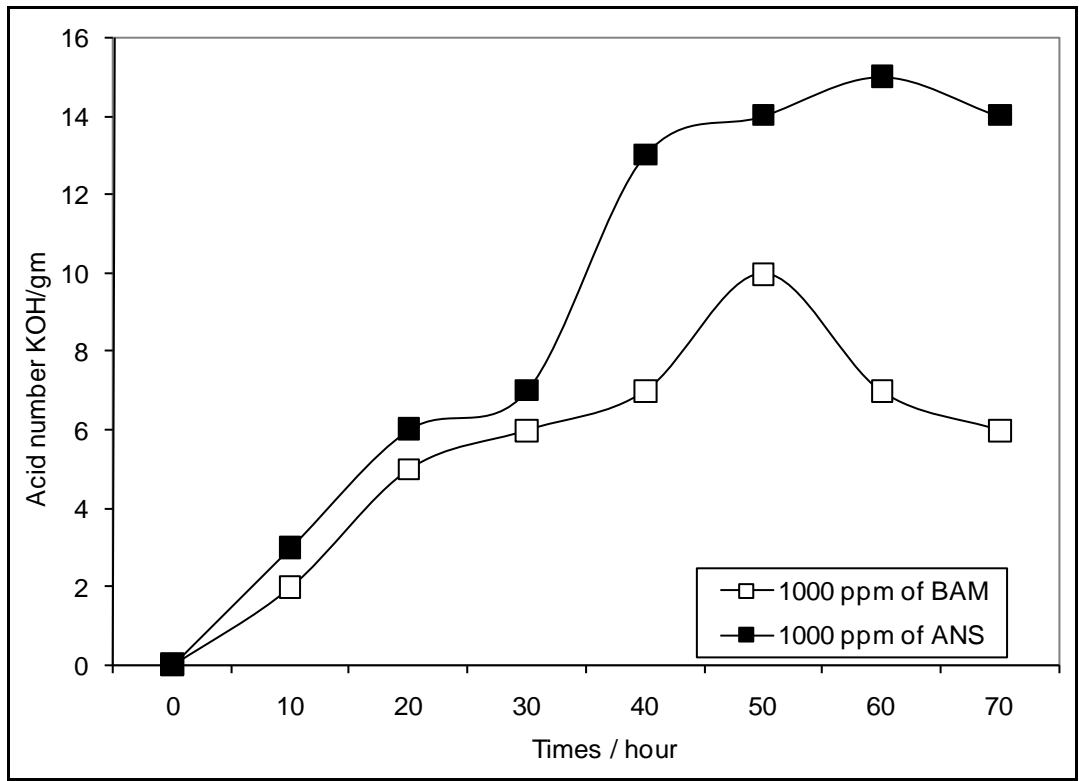

Figure 7. Effect of different inhibitors on oxidation stability of metal working fluid at concentration $1000 \mathrm{ppm}$ and $30 \mathrm{C}$.

\section{Conclusions}

- BAM and ANS have been shown to function as corrosion inhibitors for steel in sulphuric acid media and in metal working fluids. The chemical structure affect on degree of corrosion inhibition which reflect on surface and thermodynamic properties of inhibitor.

- The oxidation stability of oil as measured by total acid number indicates that, the oxidation inhibitor efficiency follows the order.

- $\quad$ BAM> ANS. These results depend on value of surface propertiese and thermodynamic parameters of inhibitors.

- The synthesized inhibitors have a multifunction for anti corrosion and enhance oxidation stability of oil. These results depend on surface properties of the inhibitor.

\section{References}

[1] Omar, A.M.A. (2004) Micellization and Adsorption of Anionic/Nonionic Polymeric Surfactants for Metal Working Fluid at Different. Interfaces Industrial Lubrication and Tribology, 56, 171-176.

[2] Osman, M.M., Omar, A.M.A. and Al-Sabagh, A.M. (1997) Corrosion Inhibition of Benzyl Triethanol Ammonium Chloride and Its Ethoxylate on Steel in Sulphuric Acid Solution. Material Chemistry and Physics, 5013, 271-274.

[3] Abdel Hamid, Z. (1997) Surface and Thermodynamic Parameters of Some Cationic Corrosion Inhibitors Anti-Corrosion Metal and Material.

[4] Abdel Hamid, Z., Soror, T.Y., El Dahan, H.A. and Omar, A.M.A. (1998) New Cationic Surfactant as Corrosion Inhibitor Anti-Corrosion Metal and Material. 45, 306-311.

[5] Elmehbad, N. (2013) Developments of Multifunctional Additives for High Quality Lube Oil. Journal of Power and Energy Engineering.

[6] Elmehbad, N. (2013) Development Antioxidants Synthesized by Phase Transfer Catalysts for Lubricating Oil Bio Tech Conference. Expo, 12-16 May 2013.

[7] Elmehbad, N. (2013) The Development and Application of Ester for Lubricating Oil by Phase Transfer Catalysts. Oral Presentation in 19th International Colloquium, Germany, 21-23 January 2013.

[8] Elmehbad, N. (2014) Preparation of Anti Wear/Antioxidant Additives for High Quality Metalworking Fluid from Waste Petroleum Products. JESMAT.

[9] Omar, A.M.A. and Azzam, E.M.S. (2003) Relation between Adsorption of Some Anionic Surfactants on Barite and 
Solution/Air Interfaces. Surface and Interface Analysis, 35, 709-713. http://dx.doi.org/10.1002/sia.1593

[10] Omar, A.M.A. and Azzam, E.M.S. (2004) Development of Electrodeposited Chromium Composite by Amphoteric Surfactant. Industrial Lubrication and Tribology, 56, 244-247.

[11] Omar, A.M.A. (2001) Separation of Emulsifiable Oil from Solution by Surface Tension Control. Adsorption Science and Technology, 19, 91-100. http://dx.doi.org/10.1260/0263617011494006 